Volume 6, Issue 1, 1-6 Pages

Research Article | Open Access

ISSN (Online)- 2380-5706

DOI : 10.21694/2380-5706.21001

\title{
Assessment of Components, Antibacterial and Antioxidant Effects of Vernonia Amygdalina Del.
}

Sy Duong-Quy ${ }^{1,2,3}$, Trinh Tang-Le-Quynh ${ }^{1}$, Linh Nguyen-Thi-Nhat ${ }^{1}$, Linh Nguyen-Thi-Thuy ${ }^{1}$, Ha Ngo-DuyTuy $^{1}$, Tram Tang-Thi-Thao ${ }^{1}$, Toi Nguyen-Van ${ }^{1}$, Chi Nguyen-Thi-Lan ${ }^{1}$, Nguyet Do-Thi ${ }^{1}$, Ha Le-Thi-Ngoc ${ }^{1}$, Huong Cao-Thi-Thu ${ }^{1}$, Dinh Tran-Thanh ${ }^{1}$, Hung Tran-Quoc ${ }^{1 *}$

${ }^{* 1}$ Medical - Biological Research Center, Lamdong Medical College, Dalat City, Vietnam.

${ }^{2}$ Penn State Medical College, Hershey Medical Center, PA, USA.

${ }^{3}$ Pham Ngoc Thach Medical University, Ho Chi Minh City, Vietnam.

\begin{abstract}
Vernonia amygdalina Del. - Asteraceae family, is used traditionally to treat inflammation, pain, fever and cancer. This study aimed to determine the bioactive composition of leaf extracts of Vernonia amygdalina Del. for evaluating the antibacterial and anti-oxidant effects of these extracts. Analysis of the active ingredients in the aqueous extracts of Vernonia amygdalina leaves showed the presence of pharmaceutical substances such as: tannins, flavonoids, saponins, alkaloid, phenol, phytalate and oxalate. The results of determining the antibacterial activity of fresh and dried leaf extracts with concentrations of 100\%, 50\%, 25\%, 12,5\%, and 7,5\% showed that Staphylococcus aureus and Escherichia coli are very sensitive to these extracts, especially the aqueous extracts. The antioxidant activity of Vernonia amygdalina leaf and stem extracts at different concentrations was determined by the DPPH and $\beta$-carotene-linoleic acid method compared with BHA, BHT, and quercetin. A positive correlation of radical scavenging activity ( $p$ value $<0.05)$ was observed in all the extracts from Vernonia amygdalina by their electron transfer or hydrogen donating ability.
\end{abstract}

KEYWORDS: antibacteria, antibio, antioxydant, component analysis, Vernonia amygdalina

\section{INSTRUCTION}

The world is facing many health challenges due to environmental pollution, climate change and humanitarian crisis leading to outbreaks of diseases, the increase of drugresistant microorganisms,... Besides, the environment of living, working, studying and the development of science and technology makes people less and less physically active, causing a strong impact on human health. The increased incidence of obesity, stress, metabolic disorders, or premature aging is the cause of many diseases such as infections, cancer, diabetes and aging. The use of plants and natural products is beneficial in protecting against damage caused by oxidative stress, / since they are less toxic, compared to synthetic compounds in dosages. their optimal protection. Synthetic antioxidants such as butylated hydroxyl anisole (BHA) and butylated hydroxyl toluene (BHT) are harmful to the liver [22]. Therefore, the selection of natural products to protect health, against pathogens is a prerequisite for the process of discovering new materials for use as medicine.
Bitter Leaf is in Asteraceae family with the scientific name (Vernonia amygdalina Del. = Gynura procumbens (Lour.) Merr.), people in many parts of the world, especially countries in Africa such as Nigeria, Cameroon, Congo ... is used to treat many different common diseases such as pain treatment, hypertension, dyslipidemia, diabetes mellitus, cancer prevention ... with simple usage as a daily vegetable. Many studies of scientists around the world have published the effects of the Vernonia amygdalina extract such as antioxidant, anti-inflammatory, antiemetic effects of acetone extract [1], breast anti-cancer [14]. Therefore, the research conducted investigating the analgesic and anti-inflammatory effects of Bitter Leaf Vernonia amygdalina Del. are collected at.

\section{MATERIALS AND METHODS}

\section{Plant Preparation}

Vernonia amygdalina Del.- ASTERACEAE was collected from the medicinal garden of Lam Dong Medical college at 16 Ngo Quyen, Da Lat city, Lam Đong - province in Vietnam. 
After collecting, the plant was removed damaged leaves and stems, washed carefully, and cut separately into three parts (leaves, stems and rhizomes), then, dried at $45^{\circ} \mathrm{C}$ for 48 / hours, then, ground into a coarse powder sifting through sieve of $35 \mathrm{~mm}$ pore size mesh.

\section{Extraction of Vernonia Amygdalina Powder}

$200 \mathrm{~g}$ of coarse powder of each part (leaves, stems and rhizomes) was macerated in $1 \mathrm{~L}$ methanol in each the absorbed exhausted bottle with cotton on the bottom for 48 hours before filtering. The powder was covered under a filter paper, then glass marbles, and macerated by pouring slowly methanol high 5 or $6 \mathrm{~cm}$ into the bottle. The resulting filtrate was evaporated and concentrated to a paste dryness using a water bath set at $45^{\circ} \mathrm{C}$ to obtain the extract then was stored in the refrigerator below $10^{\circ} \mathrm{C}$ until required for further analysis.

The methanol extract of Vernonia amygdalina powder was ranged from strong polarity to less polar by liquid-liquid extraction techniques: dissolve the total extract into Methanol in the ratio of $1: 1 / 2$ ( $1 \mathrm{ml}$ extract: $0.5 \mathrm{ml}$ methanol); then pour water into with a ratio of 1:2 (1 ml extract: $2 \mathrm{ml}$ water). This fraction was shaked in turn with solvents of increasing polarity solutions (Diethyl ether, Ethyl acetate, n-Butanol) until no more dissolved matter mixing in the solvent, then switch to a more polar solvent. After collecting and evaporating the fractions to remove the solvent, 4 extracts (diethyl ether, ethyl acetate, n-butanol, and aqueous extract) were obtained respectively.

\section{Preliminary Component Analysis of Vernonia Amygdalina}

The fractions of diethyl ether extract, ethyl acetate, n-butanol, and aqueous extract / were analyzed to determine substances which have positive results in the preliminary survey. [4] To determine alkaloid: Dissolve each fraction in $4 \mathrm{ml}$ hydrochloric acid 1\% solution, then, divide the acid solution into 4 small test tubes, and determine alkaloid by the reagents (Mayer, Bouchardat, and Dragendorff). [4] The result of Mayer reagents is that test tube change to white precipitate and light-yellow liquid; of Bouchardat reagents is that test tube change to red-brown precipitate; and the result of Dragendorff reagents is that test tube change to redorange precipitate.

To determine flavonoid group: Using the reaction with $\mathrm{H}_{2} \mathrm{SO}_{4}$, $\mathrm{NaOH}$, and $\mathrm{FeCl}_{3}$ to determine flavon, flavonol, isoflavon, chalcon, auron, leucoantocyanidin in the ethanol extract and other extracts, and the Cyanidin reaction of Wilstatter to find the presence of flavon, flavanon, flavonol, flavanonol, xanthon in the methanol extract. [4]

To determine polyphenol group: Using the Liebermann reaction to determine anthraquinon in $\mathrm{NaOH} 10 \%$ solution. [4]
To determine coumarin: Dissolve each extract in $2 \mathrm{ml}$ alcohol $70 \%$, then divide the solution into two test tubes, and add to the first tube $0.5 \mathrm{ml} \mathrm{KOH} 10 \%$ and the second an equal amount of distilled water, finally, heat them in a water bath for 2 minutes. After the solution is cool, the reaction result was observed under $365 \mathrm{~nm}$ ultraviolet light.[4]

To determine tannin: Add 5 drops of gelatin into $2 \mathrm{~mL}$ of each extract, and stir them, compared with the certificate tube containing the filtrate and the tube containing the reagent (gelatin-salt solution). If there is a white cotton precipitate, there is tannin.[4]

To determine the terpenoid group use Liebermann Bourchard reaction; to determine the steroid - triterpenoid group use the Rosenthler reaction or Carr - Price reaction; to detect steroid using Salkowski reaction, and to determine saponin group by foaming test and Fontan - Kaudel test.[4]

Thin-layerchromatography:Thepresenceofmaincomponents in each extracts was evaluated was by chemical method with general reagent and TLC (Thin-layer chromatography) method. TLC was performed on sheets coated with layer of silica gel, and dried in room temperature for 30 mins. The solvent system I [ethyl acetate: methanol: distilled water (100:8:5)], and the solvent system II [Chloroform: methanol: distilled water (65:35:10)] were used. $10 \mu \mathrm{M}$ of each extract was spotted on the silica plates. Next, the plates were run in a chromatographic chamber for about 20 mins, saturated by $100 \mathrm{~mL}$ of solvent systems. Finally, they were visualized at $254 \mathrm{~nm}$ and $365 \mathrm{~nm}$ under UV, and by $\mathrm{FeCl} 3$ reagent. [4]

\section{Antimicrobial Activity Analysis of Vernonia Amygdalina Extracts}

The Antimicrobial activity of Vernonia amygdalina extracts was determined by the diffusion method in agar or liquid medium. Each indicator bacteria was cultured in a suitable media at $37^{\circ} \mathrm{C}$ for 24 hours. The diluted bacterial solution $(100 \mu \mathrm{l})$ was added into each media, and then $100 \mu \mathrm{l}$ of each extractor sterile paper wells (6 $\mathrm{mm}$ in diameter) containing each extract was put into them. Sterile distilled water is a control. The Petri plates or test tubes were incubated at 37.0 $\pm 0.10^{\circ} \mathrm{C}$ for 24 hours. The diameter of the inhibitory zone (mm) or turbidity bacteria was measured.

\section{Antioxidant Activity Analysis of Vernonia Amygdalina Extracts}

The antioxidant activity of the Vernonia amygdalina extracts (n-hexan, ethyl acetate, ethanol, and aqueous extract) was firstly determined by DPPH (1,1- diphenyl-2-picrylhydrazyl) on a thin plate of silica gel $\mathrm{F}_{254}$ (Merck); the extract was diluted in methanol 95\%, put on the plate, the solvent system was n-hexane: ethyl acetate (8:2), DPPH reagent $(0.001 \%$ by weight/volume) were mixed when used. Then, 
the antioxidant activity of the extract on free radicals was compared to BHA (butylated hydroxyanisole), BHT (butylated hydroxytoluene) and quercetin, measured in hydrogenincreased antioxidant activity, used as the color indicator of DPPH or $\beta$-carotene-linoleic. Each 7.5, 8.75, 10 and $11.25 \mathrm{ml}$ of Vernonia amygdalina extracts and each $0.25,0.5$, and 0.75 $\mathrm{ml}$ of BHT (in methanol) were placed in different tubes. A mixture of $5 \mathrm{ml}$ of $0.5 \mathrm{mM}$ DPPH or $\beta$-carotene-linoleic was prepared for all tubes; after 30 minutes of incubating at room temperature $\left(22-24^{\circ} \mathrm{C}\right)$, the absorbance was measured at $517 \mathrm{~nm}$ with a spectrophotometer and $1 \mathrm{ml}$ of methanol mixed with $5 \mathrm{ml}$ of $0.5 \mathrm{mM}$ DPPH or $\beta$-carotene-linoleic served as blank. [8]

\section{Statistical Analysis}

Statistical analysis was performed by using the SPSS 22.0 software (Chicago, IL, USA). Data were presented as means \pm SD. Differences were considered significant at $\mathrm{p}<0.05$ and confidence interval $\geq 95 \%$. Each experiment was repeated three times at each concentration.

\section{RESULTS AND DISCUSSION}

\section{Component Analysis of Vernonia Amygdalina}

The results of the active component analysis in the aqueous extracts of Vernonia amygdalina leaves by thinlayer chromatography (TLC) and chemical reactions were presented in Tables 1 and 2. The results showed that the components from the extracts contain phytalat, oxalat, coumarin, alkaloid, saponin, tannin, and flavonoids. The quantitative substances were relatively high, especially phytalat. The results were also presented in some previous reports.[1-3, 5, 13, 17]

Table 1. Components of Vernonia amygdalina aqueous extract.

\begin{tabular}{|l|c|}
\multicolumn{1}{c|}{ Components } & Qualitative \\
\hline Tanin & ++ \\
\hline Flavonoid & +++ \\
\hline Saponin & ++ \\
\hline Alkaloid & +++ \\
\hline Phenol & + \\
\hline Phytalat & ++++ \\
\hline Oxalat & ++ \\
\hline
\end{tabular}

$(-) \rightarrow$ Non appearce; $(+) \rightarrow$ Appear in low concentrations;

$(++) \rightarrow$ Appear in moderate concentrations; $(+++) \rightarrow$ Appear in high concentrations

Table 2. The content of quantitative substances is obtained from Vernonia amygdalina leaves diethyl ether extract by soxhlet for $2 \mathrm{~h}$.

\begin{tabular}{|c|c|c|c|}
\hline \multirow{2}{*}{ Components } & \multicolumn{3}{|c|}{ Weight (mg) } \\
\hline & Max & Min & Mean \\
\hline Tannin & 3,31 & 3,27 & $3,288 \pm 0,012^{*}$ \\
\hline Flavonoid & 4,06 & 4,03 & $4,044 \pm 0,011$ \\
\hline Saponin & 3,59 & 3,51 & $3,552 \pm 0,027$ \\
\hline Alkaloid & 3,81 & 3,65 & $3,732 \pm 0,054$ \\
\hline Phenol & 1,62 & 1,54 & $1,582 \pm 0,026$ \\
\hline Phytalat & 19,62 & 18,58 & $19,402 \pm 0,316$ \\
\hline Oxalat & 3,67 & 3,42 & $3,511 \pm 0,083$ \\
\hline
\end{tabular}

$*$ Data were presented as means \pm SD at $\mathrm{p}<0.05$ and confidence interval $\geq 95 \%$.

Antimicrobial Activity of Vernonia Amygdalina Extracts

The results in Figure 1 and Table 3 indicated that all three extracts (ethanol extract, hot aqueous extract, and soup extract) inhibited the growth of E. coli and S. aureus. It also showed that hot aqueous extract had the highest inhibitory zone on E. coli and $S$. aureus compared with the control substance Ampicillin $(\mathrm{P}<0.001)$. This is followed by the inhibitory effect of Vernonia amygdalina leaf extract on $E$. coli, which is significantly higher than the inhibitory effect of Ampicillin on $S$. aureus $(\mathrm{P}<0.001)$ and also higher than the inhibitory effect of Ampicillin on E. coli $(\mathrm{P}=0.025)$. From the isolates were determined based on the study results at Slovenia of Comenius University performed [1]. This is similar to the research of scientists around the world. [4, 6, 7, 9-12, 15, 18-21] 


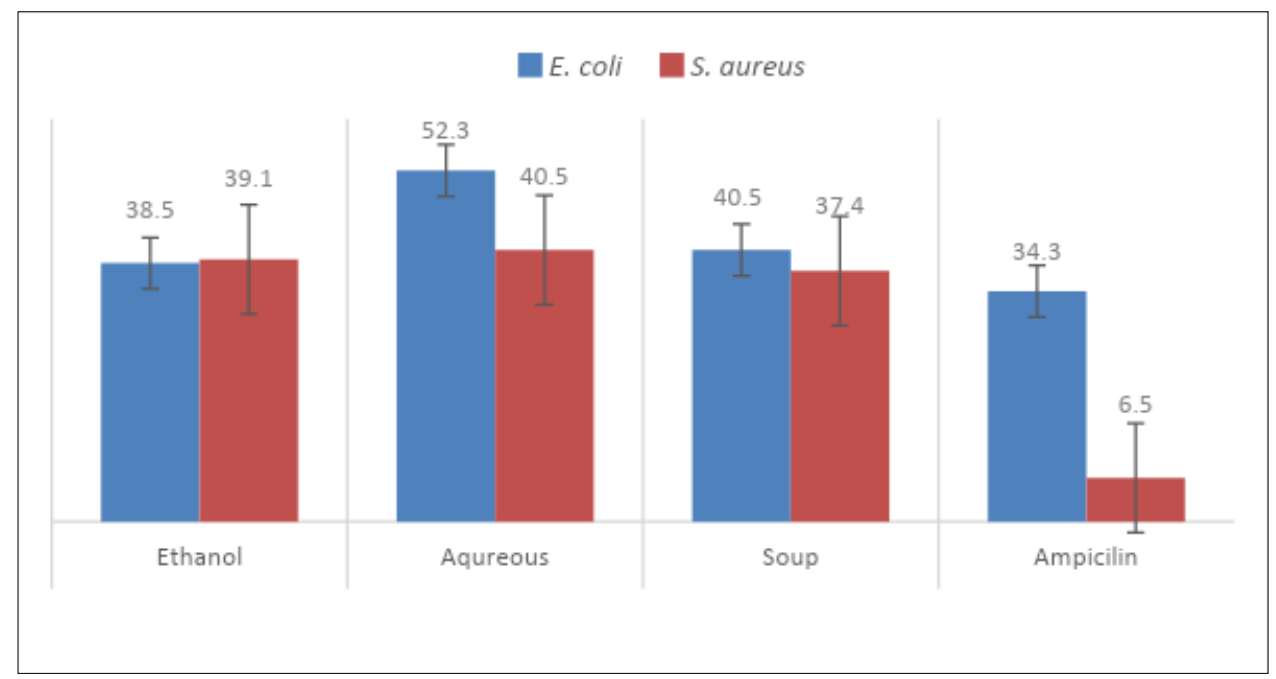

Figure 1. Antimicrobial activity of Vernonia amygdalina extracts

Table 3. Morphological and biochemical characteristics of the tested strains.

\begin{tabular}{|c|c|c|}
\hline $\begin{array}{ll}\text { Media } & \text { Bacteria } \\
\end{array}$ & Staphylococcus aureus & Escherichia coli \\
\hline Gram & +++ & - \\
\hline Lactose & - & + \\
\hline Manitol & - & + \\
\hline Glucose & - & + \\
\hline
\end{tabular}

(-) No; (+) low positive; (+++) high positive

Antioxidant Activity of Vernonia Amygdalina Extracts

\section{DPPH Testing}

The antioxidant kinetics and mechanism of the antioxidant activity of $V$. amygdalina were analyzed by testing DPPH and using the spectroscopic method (Figure 2). The methanolic extracts of the leaves contain the phenolic antioxidant that is the primary agent responsible for their DPPH scavenging activities. The determination of the antioxidant activity of
Vernonia amygdalina is likely due to the hydroxyl groups present in the chemical structure of the phenolic compounds that can provide the necessary ingredients as a free radical and antioxidant. Antioxidant activity depends not only on the concentration of the antioxidant, but also on the structure and interactions between antioxidants. The antioxidant activity is attributed to a different mechanism. Specifically, prevention of chain formation, metal ion catalyst binding, peroxide degradation, prevention of hydrogen abstraction and free radical scavenging.

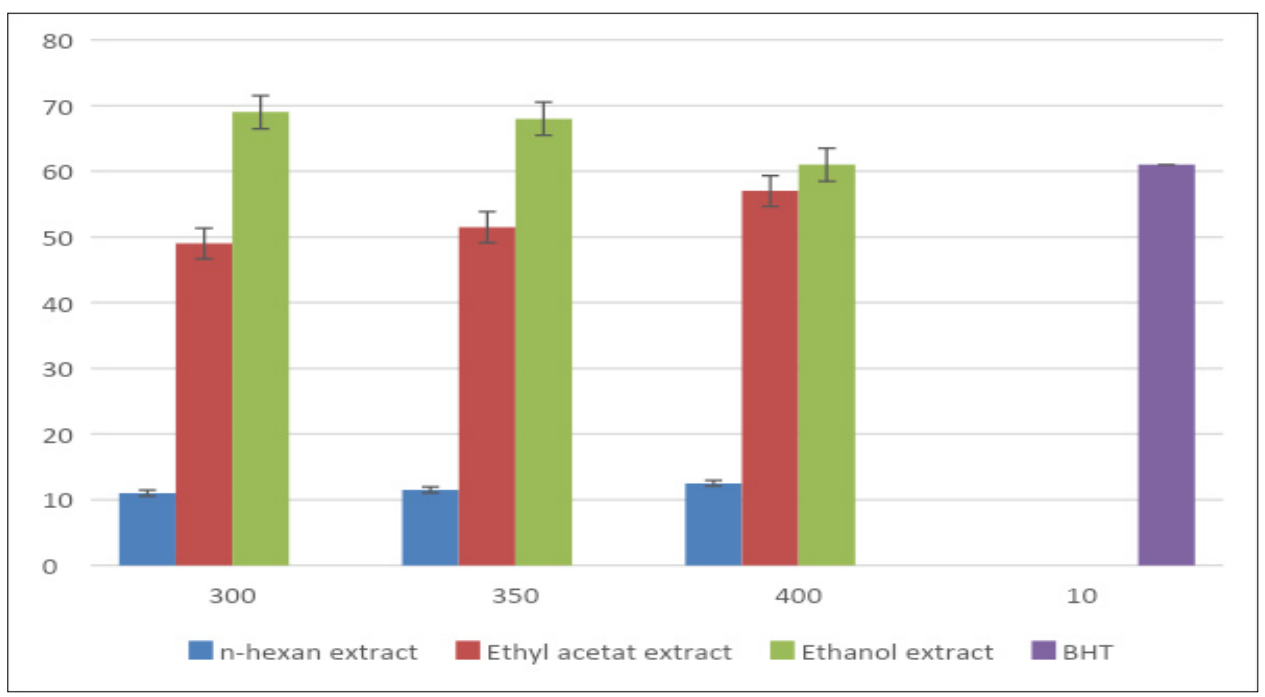

Figure 2. Antioxidant activity of leaf and stem extracts of Vernonia amygdalina at different concentrations were analyzed by DPPH method and compare to BHT. Each value presents one type of extract \pm SD $(n=3) ; p<0.05$. 


\section{$\beta$-Caroten-Linoleic Testing}

The antioxidant activities of the Vernonia amygdalina extracts, BHA, BHT, and quercetin, as measured by the discoloration of $ß$-carotene, are shown in Figure 3. It can be seen that leaf and stem extract. The leaves are bitter in varying degrees of antioxidant activity. The antioxidants of the Vernonia amygdalina extracts and the titrant increase in the order $\mathrm{BHA}>\mathrm{BHT}>$ quercetin > ethanol extract> ethyl acetate extract>n-hexane extract. The ethyl acetate extracts of Vernonia amygdalina, $400 \mathrm{mg} / \mathrm{ml}$ showed the highest antioxidant activities. The n-hexane extracts also have antioxidant activity. The ethanol and ethyl acetat extract of Vernonia amygdalina have the same antioxidant activity, using quercetin to control the extracts. The antioxidant activities of Vernonia amygdalina were influenced by the solvent used for extraction and analytical methods.

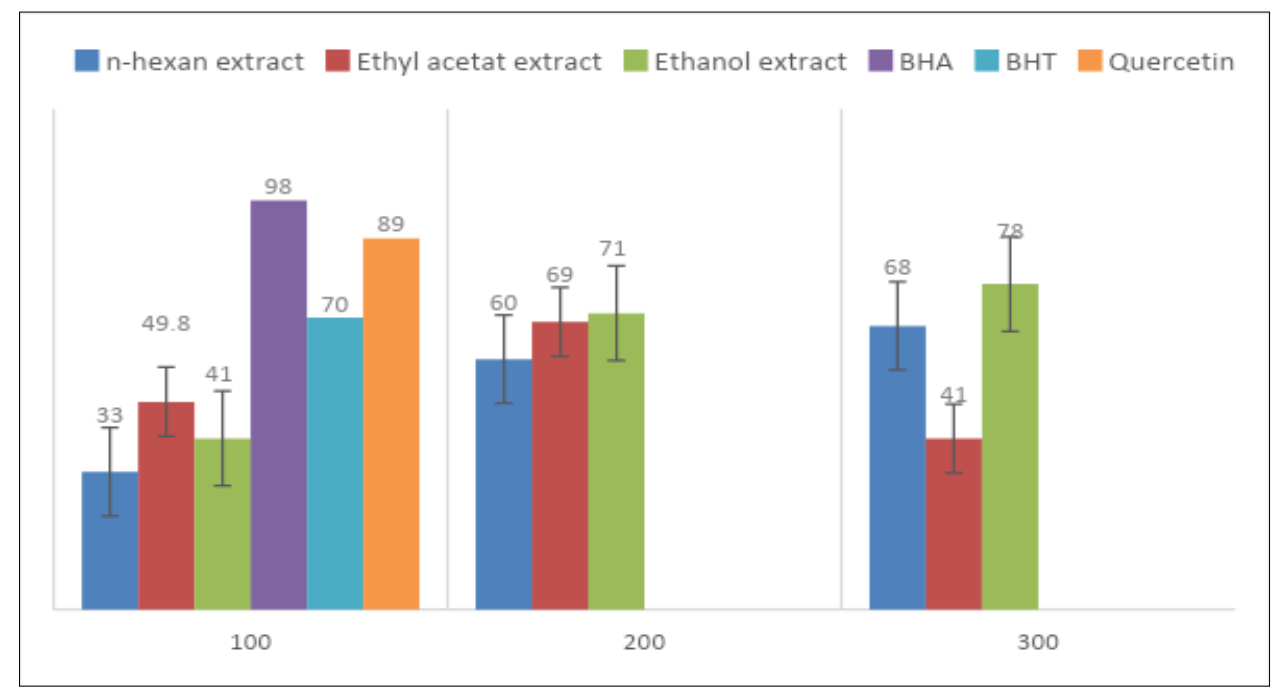

Figure 3. Effect of concentration of leaf and stem extracts of Vernonia amygdalina on antioxidant activity with $ß$-carotene -linoleic acid method compare with BHA, BHT, and with quercetin.. Each value represents an extraction method \pm SD.

The extracts of Vernonia amygdalina in this study showed different levels of antioxidant activity. The results showed that the ethyl acetate extract exhibited the highest antioxidant activity with the $ß$-carotene method. Meanwhile, the ethanol extracts showed the strongest antioxidant activity with the DPPH testing. Differing the method for measuring antioxidant activity can lead to different results. The solvent extracts influence the yield and antioxidant activity of the Vernonia amygdalina extract. The results of this study show a correlation with previous studies by Grierson et al. (2007) [8], Tangka (2003) [21], Moody et al. (2003) [16].

\section{CONCLUSION}

Vernonia amygdalina extracts contain organic compounds with common pharmacological effects in plants such as tannins, flavonoids, saponins, alcalids, phenols, phytalates, oxalates. Results show that 20 g of Vernonia amygdalina contains $3.29 \mathrm{~g}$ tannin, $4.044 \mathrm{~g}$ flavonoid, 3.55 saponin, $3.73 \mathrm{~g}$ alkaloids, $1.58 \mathrm{~g}$ phenol, $19.402 \mathrm{~g}$ phytalate, $3.511 \mathrm{~g}$ Oxalate. Antibacterial effect of Vernonia amygdalina hot aqueous extract is the highest inhibitory zone on E. coli and $S$. aureus compared with Ampicillin. Antioxidant activity of leaf and stem extracts at different concentrations were presented the highest at ethanol extract by DPPH testing and ß-carotene -linoleic testing.

\section{REFERENCES}

1. Adewole E, Ojo A, Ogunmodede OT, Adewumi DF. Antioxidant activities and nutritional compositions of
Vernonia amygdalina. International Journal of Basic and Applied Science 2015; 4:9-16.

2. Alabi DA, Onibudo MZ, Amusa NA. Chemicals and nutritional composition of four botanicals with fungi toxic properties. World J Agric Sci 2005; 1:84-8.

3. Alemika Emmanuel Taiwo Sani Ali Audu ARO. Study review of documented phytochemistry of Vernonia amygdalina (Family Asteraceae) as the basis for pharmacologic activity of plant extract. Journal of Natural Sciences Research 2012; 2:2224-3186.

4. Atangwho IJ, Ebong PE, Egbung GE, Eteng MU, Eyong EU. Effect of Vernonia amygdalina Del. on liver function in alloxan-induced hyperglycaemic rats. J Pharm Bioresour 2007; 4:1-7.

5. Audu SA, Taiwo AE, Ojuolape AR, Sani AS, Bukola AR, Mohammed I. A study review of documented phytochemistry of Vernonia amygdalina (Family Asteraceae) as the basis for pharmacologic activity of plant extract. Journal of Natural Sciences Research 2012; 2:1-9.

6. Awe SO, Makinde JM, Olajide OA. Cathartic effect of the leaf extract of Vernonia amygdalina. Fitoterapia 1999; 70:161-5.

7. De Carvalho PB, Ferreira EI. Leishmaniasis phytotherapy. Nature's leadership against an ancient disease. Fitoterapia 2001; 72:599-618. 
8. Erasto P, Grierson DS, Afolayan AJ. Antioxidant constituents in Vernonia amygdalina. Leaves. Pharmaceutical Biology 2007; 45:195-9.

9. Garba H, Putaya HAN, Mustapha BUA, Galadima WA. Phytochemical and physico-chemical analysis of air dried and fresh samples of Vernonia amygdalina leaf. Applied Research Journal 1394; 1:433-6.

10. Hettiarachchy NS GK, Gnanasambandam R, Jonhnson MG. Natural antioxidant extracts from Fenugreek (Trigonella foenumgraecum) for ground beef patties. J Food Sci 2010; 61:516-9.

11. Igbakin AP, Oloyede OB. Comparative studies on the hypoglycaemic, hypoproteinaemic, hypocholesterolaemic and hypolipidaemic properties of ethanolic and normal saline extracts of the root of Vernonia amygdalina in diabetic rats. Adv Environ Biol 2009; 3:33-8.

12. Iroanya $\mathrm{O}$, Okpuzor J, Mbagwu H. Anti-nociceptive and anti-phlogistic actions of a polyherbal decoction. IJPInternational Journal of Pharmacology 2010; 6:31-9.

13. Jisaka $M$, Ohigashi $H$, Takegawa $K$, Hirota $M$, Irie $R$, Huffman MA, et al. Steroid glucosides from Vernonia amygdalina, a possible chimpanzee medicinal plant. Phytochemistry 1993; 34:409-13.

14. Malík I, Csöllei J, Jampílek J, Stanzel L, Zadražilová I, Hošek J, et al. The structure-antimicrobial activity relationships of a promising class of the compounds containing the $\mathrm{N}$-arylpiperazine scaffold. Molecules 2016; 21:1274.

15. Ofori DA, Anjarwalla P, Jamnadass R, Stevenson PC, Smith P. Pesticidal plant leaflet Vernonia amygdalina Del. Royal botanic garden 2013:1-2.

16. Ogundipe OO, Moody JO, Akinyemi TO, Raman A. Hypoglycemic potentials of methanolic extracts of selected plant foods in alloxanized mice. Plant Foods for Human Nutrition 2003; 58:1-7.
17. Ohigashi H, Jisaka M, Takagaki T, Nozaki H, Tada T, Huffman M, et al. Bitter principle and a related steroid glucoside from Vernonia amygdalina, a possible medicinal plant for wild chimpanzees. Agricultural and Biological Chemistry 1991; 55:1201-3.

18. Pesewu GA, Cutler Rr Fau - Humber DP, Humber DP. Antibacterial activity of plants used in traditional medicines of Ghana with particular reference to MRSA. J Ethnopharmacol 2008; 116:102-11.

19. Reuben Okoduwa S, Umar I, James D, Inuwa H. Validation of the antidiabetic effects of Vernonia amygdalina delile leaf fractions in fortified diet-fed streptozotocin-treated rat model of type-2 diabetes. Journal of Diabetology 2017; 8:74-85.

20. SweeKeong Y, WanYong H, BoonKee B, WoonSan L, Huynh K, Hadi NA, et al. Vernonia amygdalina, an ethnoveterinary and ethnomedical used green vegetable with multiple bio-activities. Journal of Medicinal Plants Research 2010; 4:2787-812.

21. Tangka JK. Analysis of the thermal energy requirements for the extraction of leaf protein concentrate from some green plants. Biosystems Engineering 2003; 86:473-9.

22. Vlietinck AJ, Van Hoof L Fau - Totté J, Totté J Fau - Lasure A, Lasure A Fau - Vanden Berghe D, Vanden Berghe D Fau - Rwangabo PC, Rwangabo Pc Fau - Mvukiyumwami J, et al. Screening of hundred Rwandese medicinal plants for antimicrobial and antiviral properties. J Ethnopharmacol 1995; 46:31-47.

23. Study of active compounds of Plectranthii Amboinicii leaves growing in Dalat City, Vietnam and its antibacterial and antioxidant activities T Tang-Le-Quynh, H Ngo-DuyTuy, K Mai-Thanh, World J Pharm Pharm Sci, 2017.

Citation: Sy Duong Quy, Trinh Tang Le Quynh, Linh Nguyen Thi Nhat, et al., "Assessment of Components, Antibacterial and Antioxidant Effects of Vernonia Amygdalina Del.", American Research Journal of Pharmacy, Vol 6, no. 1, 2021, pp. 1-6.

Copyright (C) 2021 Sy Duong Quy, Trinh Tang Le Quynh, Linh Nguyen Thi Nhat, et al., This is an open access article distributed under the Creative Commons Attribution License, which permits unrestricted use, distribution, and reproduction in any medium, provided the original work is properly cited. 